\title{
IMPACT ANALYSIS OF URBANIZATION ON LAND USE LAND COVER CHANGE FOR KHULNA CITY, BANGLADESH USING TEMPORAL LANDSAT IMAGERY
}

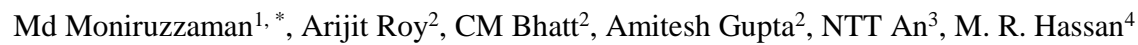 \\ ${ }^{1}$ Center for Space Science and Technology Education in Asia and the Pacific, Dehradun, India - moniruzzaman1313ku@gmail.com \\ ${ }^{2}$ Indian Institute of Remote Rensing, Dehradun, India - (arijitroy, cmbhaatt)@iirs.gov.in, amitesh13gupta14@gmail.com \\ ${ }^{3}$ National Remote Sensing Department of Vietnam, 83 Nguyen Chi Thanh Street, Ha Noi, Vietnam, ngtranan.rsc@ gmail.com \\ ${ }^{4}$ Faculty of Physics, Northern University of Business and Technology, Khulna, Bangladesh, robifagun@ yahoo.com
}

Commission V, SS: Infrastructure and Development Planning

KEY WORDS: Corner Reflector, Radar Cross Section, Trihedral, Dihedral, Compact Antenna Test Range Facility, Calibration

\begin{abstract}
:
Urbanization has given a massive pace in Land Use Land Cover (LULC) changes in rapidly growing cities like Khulna, i.e. the third largest city of Bangladesh. Such impacting changes have taken place in over-decadal scale. It is important because detailed analysis with regularly monitoring will be fruitful to drag the attention of decision maker and urban planner for sustainable development and to overcome the problem of urban sprawl. In this present study, changes in LULC as an impact of urbanization, have been investigated for years 1997, 2002, 2007, 2012 and 2017; using three generation of Landsat data in geographic information system (GIS) domain which has the height competence in recent time. Initially, LULC have categorised into Built-up, Vegetation, Vacant Land, and Waterbody with the help of supervised classification technique. Field work had been carried out for acquiring training dataset and validation. The accuracy has been achieved more than $85 \%$ for the changes assessed. Analysis has an outlet with increase in built-up area by $27.92 \%$ in year 1997 to 2017 and continued respectively in each successive interval of half a decade at the given years. On the other side waterbody and vacant land decreased correspondingly. Bound to mention, instead to having largest temporal durability, the moderate spatial resolution of Landsat data has a limitation for such urban studies. These changes are responsible by both of natural or anthropogenic factors. Such study will provide a better way out of optimization of land-use to prepare detail area plan (DAP) of Khulna City Corporation (KCC) and Khulna development authority (KDA).
\end{abstract}

\section{INTRODUCTION}

The LULC pattern of a city is resultant of natural, socioeconomic factors and utilization in time and space by the inhabitants. LC refers to the physical and biological cover over the surface of land, including water, vegetation, bare soil, etc. Land Use has been defined in terms of human activities such as development activity, agriculture, forestry and building construction that alter land surface processes including biogeochemistry, hydrology and biodiversity (Sajjad \& Iqbal, 2012). Over recent decades, developing countries are characterized by a decrease in rural land use and an increase in urban land use through urbanization (Dewan \& Yamaguchi 2009a; Jat et al., 2008; Mundia \& Aniya 2006; Yin et al., 2011). At very present, urban areas spikes only $3 \%$ of the Earth's land surface but accommodate over half of the world's population (Herold et al., 2003; Liu \& Lathrop 2002; United Nations 2001). Anthropogenic activities in cities have brought significant changes in LULC pattern at both local and global scales. Satellite remote sensing has been widely applied in detecting LULC change especially urban expansion and cropland loss (Sajjad \& Iqbal, 2012). There are a number of methods to detect changes in LULC from remotely sensed data such as selective principal components analysis, vegetation index differencing, image differencing, direct multi-date classification, univariate image differencing, image ratioing, change vector analysis and post-classification and so on (Mas, 1999; Yang \& Lo, 2002; Sajjad \& Iqbal, 2012). Among all of these the most common used methods for LULC change is postclassification.

Urbanization is one of the most obvious human induced global changes worldwide. In the last 200 years, the world population

\footnotetext{
* Corresponding author
}

has increased 6 times and the urban population has multiplied 100 times (Kashem, 2008). Like many other cities in the world Khulna, the third largest metropolitan city of Bangladesh, is also the outcome of spontaneous rapid growth without any prior or systematic planning. As the growth of population in Khulna is taking place at an exceptionally rapid rate $3.8 \%$ growth rate (Khan, 2012). The city has undergone radical changes through both vast territorial expansion and internal physical transformations over the last decades. Which have created exclusively new kinds of robustness in urban texture. In the process of urbanization, the physical characteristics of Khulna city are gradually changing as low land and water bodies have been transformed into reclaimed built-up lands, open spaces into building areas, agricultural land into built-up lands, decreasing water body (Moniruzzaman \& Azim, 2017) etc. The impact of the urbanization has to be analyzed to understand the changes in LULC that have led to the growth of Khulna city as the city has recorded massive urbanization over last two decades such that sustainable land use and eco-environmental restoration planning can be formulated by policy makers.

\section{STUDY AREA}

Located in the south-west Bangladesh, Khulna metropolitan city, consisting 31 municipal wards, with a geographical boundary range from $22^{\circ} 46^{\prime}$ to $22^{\circ} 58^{\prime}$ North latitude, $89^{\circ} 28^{\prime}$ to $89^{\circ} 37^{\prime}$ accommodate total population of 663,432 with $11,000 / \mathrm{sq} . \mathrm{km}$. in 59.57 sq. km. area (population \& Housing Census 2011). The city has Bhairab and Mayur river in the north, Hatia and Pasur river in the south while Rupsa river in the central region of the city (Roy et al., 2005). Khulna has humid summer and pleasant winter type of climate with annual average temperature of $26.3^{\circ} \mathrm{C}\left(79.3^{\circ} \mathrm{F}\right)$ and monthly means varying between $12.4^{\circ} \mathrm{C}\left(54.3^{\circ} \mathrm{F}\right)$ in January and $34.3^{\circ} \mathrm{C}$ $\left(93.7^{\circ} \mathrm{F}\right)$ in May while the annual average rainfall is $1,809.4$ 
mm. (71.24 inches) (Bangladesh Meteorological Department, 2016).

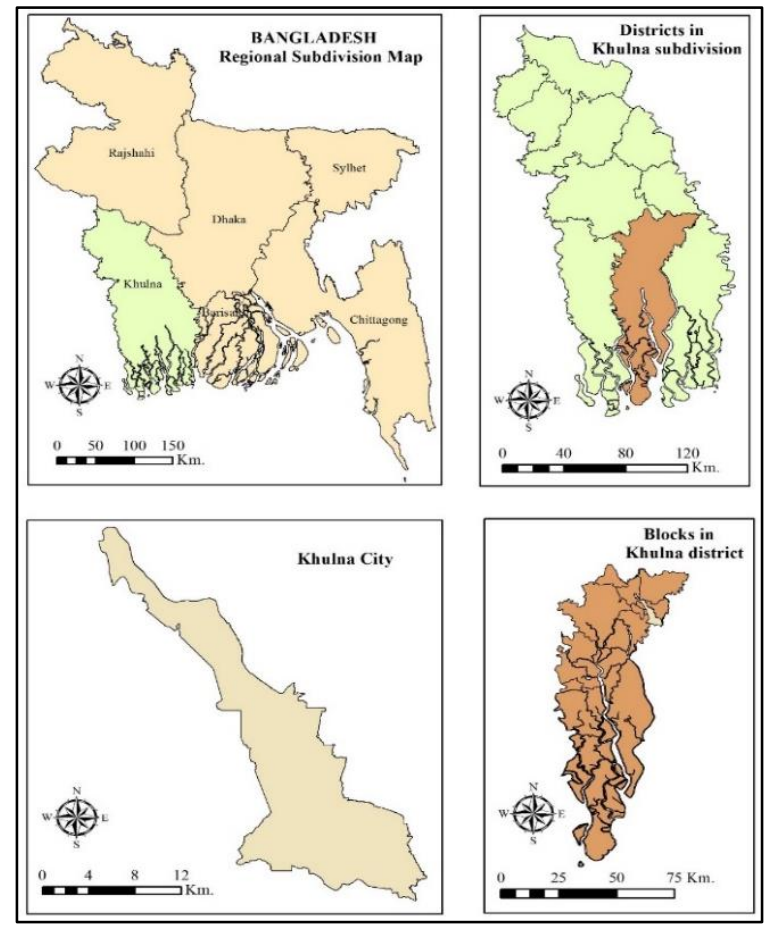

Figure 1. Study Area

\section{METHODOLOGY}

The first phase of the study involved the collection of data that covered the study area and the preparation of the LU/LC layers for two decades. Landsat images were selected from among the various levels of spatial, spectral, radiometric and temporal resolution satellite images because of their long-term availability and cost-effectiveness. The LU/LC layers were generated by using satellite images of Landsat-8 (OLI), Landsat-7 (ETM+) and Landsat-5 (Table 1) to identify the LULC changes over the period of 1997 to 2017. All images were obtained from the website of USGS (http://earthexplorer.usgs.gov/) and were dry season images. In the second phase, the LU/LC changes were analyzed and the impact of urbanization due to subsequent LULC changes also analyzed. The imagery was classified into four separate LULC classes were built-up, vegetation, vacant land and water body. Table 2 highlights the LULC features included for each class.

Table 1. Characteristics of Landsat data sets for the study.

\begin{tabular}{lll}
\hline Date of Acquisition & $\begin{array}{l}\text { Landsat } \\
\text { Sensor }\end{array}$ & Spatial Resolution \\
\hline 01 January, 2017 & OLI & 30 meter \\
24 February, 2002 & ETM+ & 30 meter \\
12 January, 2012 & ETM+ & 30 meter \\
06 January, 2007 & ETM+ & 30 meter \\
01 January, 1997 & TM & 30 meter \\
\hline
\end{tabular}

Table 2. LULC Classes Considered in the study.

\begin{tabular}{ll}
\hline Class & Features \\
\hline Built-Up & Residential, industrial, transportation \\
& networks, and commercial infrastructures. \\
Vegetation & Trees, parks, grasslands, plantations. \\
Vacant Land & Vacant lands, bare soils, sand, playgrounds.
\end{tabular}

Water Body Lakes and coastal water.

To classify the LULC from the three pre-processed Landsat images, the supervised classification technique was used.

To examine the classification accuracies, 365 ground truth reference points were sampled (through stratified random sampling method) across the study area. The classified results had overall accuracies of $85 \%$ (1997), 86\% (2002), 91\% (2007), $86 \%$ (2012), and 94\% (2017) with Kappa coefficients of 0.84 , 0.85, 0.90, 0.85, and 0.94. Besides that, Google Earth Engine and some others source data (Khulna Development Authority, Khulna City Corporation, Detail Area Plan \& open source website) are used to validate major land use features.

\section{RESULTS AND DISCUSSIONS}

By analysing the progressive change (\%) in LULC during 2002, 2007, 2012, 2017 with respect to 1997 (Figure 2) and progressive trend of change (\%) LULC (Figure 3) it is found that from 1997 to 2017 , the amount of vacant land declined consistently by $13.55 \%$. During the same period, the built-up area increased by 6522 ha $(27.92 \%)$ of the study area. The amount of vegetation increased from the years 2002 to 2007 by 1343 ha i.e. $5.85 \%$ in the study area.

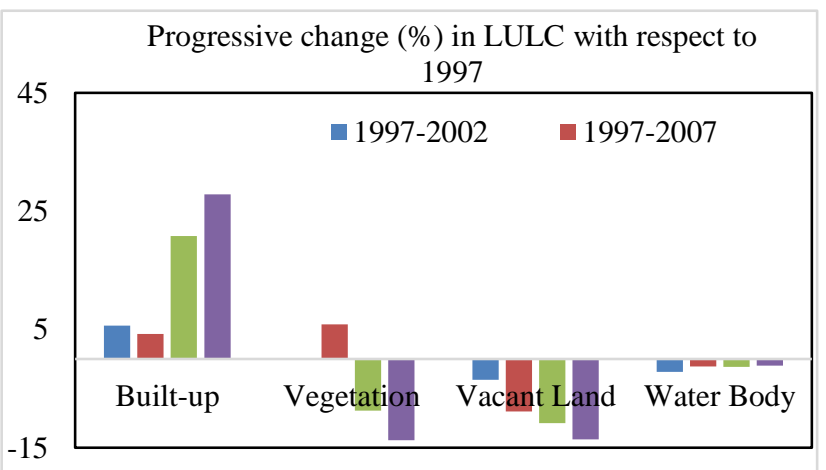

Figure 2. LULC Change (\%) with Respect to 1997

However, significant decrease in vegetation observed in the years 2007 to 2012 and 2017 by $14.56 \%$ and $19.56 \%$ of the study area accordingly. And changes among classes between the year 1997 and 2017 is provided in Table 3. Finally, the areas of water body slightly increased by 209 ha $(0.90 \%)$ and 370 ha $(1.06 \%)$ of the study area in the year 2002 to 2007 and

Progressive Trend of change in LULC

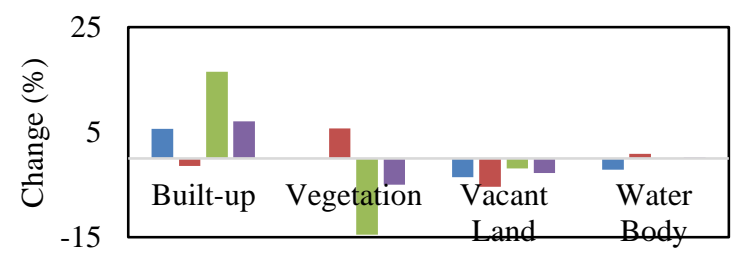

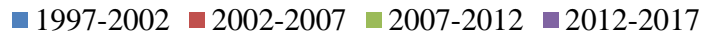

Figure 3. Trend of Change (\%) in LULC

2017; and decreased by 137 ha $(1.12 \%)$ of the study area from 1997 to 2017 (Figure 4).

Table 3. Change matrix of LULC (1997-2017) 


\begin{tabular}{|c|c|c|c|c|c|c|}
\hline \multicolumn{7}{|c|}{2017} \\
\hline \multirow[b]{6}{*}{$\hat{\sigma}$} & & W. B & Veg. & B-U & V. L & G. T \\
\hline & W. B & 2606 & 156 & 419 & 130 & 3311 \\
\hline & Veg. & 249 & 3554 & 3552 & 867 & 8222 \\
\hline & B-U & 94 & 768 & 4129 & 400 & 5391 \\
\hline & V. L & 225 & 538 & 3813 & 1857 & 6433 \\
\hline & G. T & 3174 & 5016 & 11913 & 3254 & 23357 \\
\hline
\end{tabular}

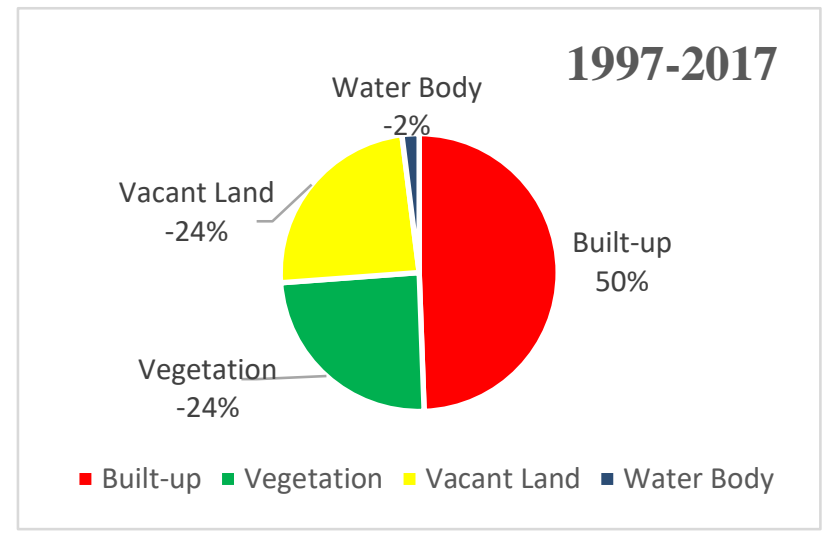

Figure 4. Areal Distribution (\%) of LULC 1997-2017

LULC spatial distribution and change map for the years 1997 , 2002, 2007 and 2017 is shown in figure 5.

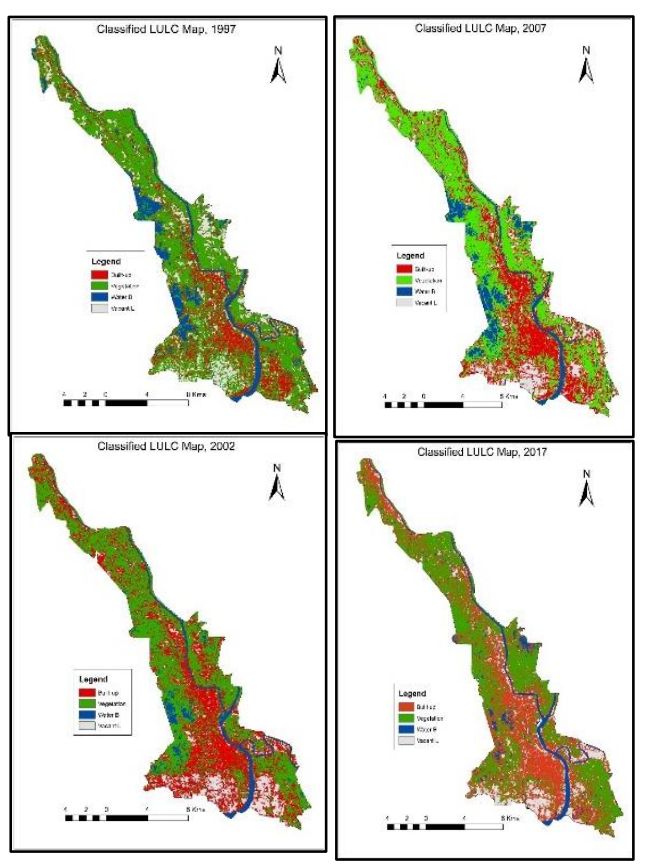

Figure 5. LULC Change Map

\section{CONCLUSION}

This study compared six separate Landsat images acquired by three different sensors to evaluate LULC changes during last two decades in Khunla city, Bangladesh where urbanization is beginning to explode. It also examined the trends in the LULC changes during these periods and their intra class relationships among LULC classes. Since 1997 to 2017, the built-up area in Khulna has increased, resulting in contentious decreasing vegetation and vacant land. If such a trend continues, built-up areas will paved the most of the ground surface within this city area. Such increases in built up areas along with their temperatures will have numerous heterogeneous medical, environmental, and social impacts and consequences. The results of this study will be considered by city planners, managers and all organizations involved in the decision-making process regarding land use and the creation of prospective land use policies for environmental sustainability, protection of natural resources and preparation of future city master plan.

\section{REFERENCES}

Bangladesh Meteorological Department.

2016. http://bmd.gov.bd/p/Monthly-Minimum-MaximumTemperature/Normal-Monthly-Rainfall/ (Last Accessed 12 September, 2018)

Dewan, A. M., and Yamaguchi, Y., 2009a. Land Use and Land Lover Change in Greater Dhaka, Bangladesh: Using Remote Sensing to Promote Sustainable Urbanization. Applied Geography, doi:10.1016/j.apgeog.2008.12.005.

Herold, M., Goldstein, N. C., and Clarke, K.C., 2003. The Spatiotemporal form of Urban Growth: Measurement, Analysis and Modeling. Remote Sensing of Environment 86, 286- 302.

Jat, M. K., Garg, P. K., and Khare, D., 2008. Monitoring and Modeling of Urban Sprawl using Remote Sensing and GIS Techniques. International Journal of Applied Earth Observation and Geoinformation, 10(1), 26-43.

Kashem, M.S.B., 2008. Simulating Urban Growth Dynamics of Dhaka Metropolitan Area: A Cellular Automata Based Approach. Master's Thesis, Department of Urban and Regional Planning, Bangladesh University of Engineering and Technology (BUET), Dhaka, Bangladesh.

Khan, M.S.A., 2012. Urban and Peri-Urban Water Management Nexus to a Dying River, IDRC Seminar, New Delhi.

Liu, X., and Lathrop, J.R.G., 2002. Urban Change Detection Based on an Artificial Neural Network. International Journal of Remote Sensing, 23, 2513-2518.

Mas, J.F., 1999. Monitoring Land-Cover Changes: A Comparison of Change Detection Techniques. International Journal of Remote Sensing, 20(1), 139-152.

Moniruzzaman, M., and Azim, S., 2017. Time Series analysis to observe the Revitalization of Mayur River Using Landsat Images in Khulna City Bangladesh, 37th Asian Conference on Remote Sensing, New Delhi.

Mundia, C. N., and Aniya, M., 2006. Dynamics of Land Use/Cover Changes and Degradation of Nairobi city, Kenya. Land Degradation and Development 17(1), 97-108.

Population and Housing Census. 2011. Bangladesh Bureau of Statistics. p. 44. 
Roy, M.K., Datta, D.K., Adhikari, D.K., Chowdhury, B.K., and Roy, P.J., 2005. Geology of the Khulna City Corporation, J. Life Earth Science, Vol. 1(1): pp.57-63.

Sajjad, H. and Iqbal, M., 2012. Impact of Urbanization on Land Use/Land Cover of Dudhganga Watershed of Kashmir Valley, India, International Journal of Urban Sciences, 16:3, 321-339, http://dx.doi.org/10.1080/12265934.2012.743749.

United Nations. 2001. The state of the World's Cities, 2001. United Nations Centre for Human Settlements, Nairobi, Kenya.

Yang, X., and Lo, C.P., 2002. Using a Time Series of Satellite Imagery to Detect Land Use and Land Cover Changes in the Atlanta, Georgia Metropolitan area. International Journal of Remote Sensing, 23, 1775-1798.

Yin, J., Yin, Z., Zhong, H., Xu, S., Hu, X., Wang, J., and Wu, J., 2011. Monitoring Urban Expansion and Land Use/Land Cover Changes of Shanghai Metropolitan Area during the Transitional Economy (1979-2009) in China. Environmental Monitoring and Assessment, 177, 609-621. 